\title{
Administering the Marine Environment - the Spatial Dimension
}

\author{
A. Rajabifard
}

\author{
A. Binns \\ I. Williamson
}

\begin{abstract}
Administering the spatial dimension of the marine environment is very important as decision-makers in both land and marine related areas of the coastal zone need to access marine related datasets in order to effectively achieve their economic, social and environmental objectives. There is also the challenge of managing the complex interactions between, and competing rights of, stakeholders within the marine environment.
\end{abstract}

This paper aims to discuss both the current and future direction of marine administration, including

\section{A. Rajabifard}

\section{A. Binns \\ I. Williamson}

Centre for Spatial Data Infrastructures and Land Administration

Department of Geomatics

The University of Melbourne

VictoriaAUSTRALIA3010

abbas.r@unimelb.edu.au

a.binns@unimelb.edu.au

ianpw@unimelb.edu.au the development of a Spatial Data Infrastructure (SDI) as a tool to achieve efficientmanagement, concentrating on Asia and the Pacific region. This includes the socioeconomic, policy and technical challenges and issues faced by countries within this jurisdiction, as well as an overview of the objectives, principle tasks and results of the 'International Workshopon Administering the Marine Environment - the Spatial Dimensions', held in Malaysia in 2004. Althoughfocusing on Asia and the Pacific region, the results and conclusions drawn from this paper can also be applicable toother marine jurisdictions.

\section{INTRODUCTION}

Marine and coastal spaces are extremely complex environments, subject to conflicting pressures and demands, including economic development, social interaction and the need to protect crucial ecosystems and ocean habitats. The marine environment also contains a wealth of actual and potential resources, with demand for exploitation increasing rapidly. In order to balance conflicting ocean uses, resource and coastal management and marine development, a governance framework is required which must be sustainable, holistic and informed (Figure 1).

Underpinning this governance framework is the complex interaction between overlapping and sometimes competing rights, restrictions and responsibilities of various activities within the marine 


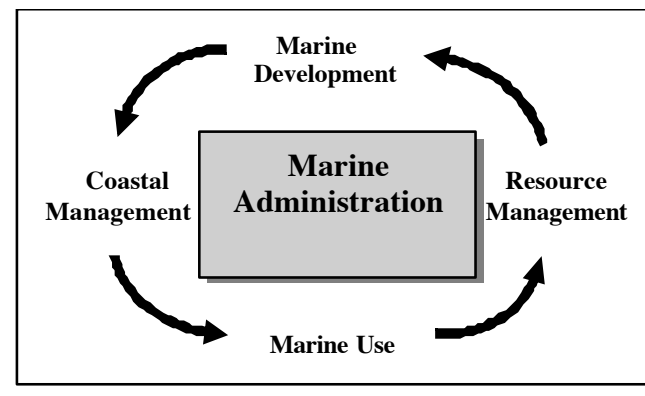

Figure 1. Features of Marine Administration

environment and at the coastal zone. It is now being accepted that much of the required information needed to balance these competing interests has an inherent spatial dimension, which offers both potential and challenges for proper analysis and management (PCGIAP-WG3, 2004). The current jurisdictional zones that make up the world's oceans are listed in Table 1, as defined by the United Nations Convention on the Law of the Sea(UNCLOS).

The current systems in place to manage and administer marine boundaries and rights need to be assessed in order to identify technical, legal and institutional issues and arrangements that are hindering the coordination andeffective management of the marine environment. International perspectives also need to be considered, if the ability to create a marine administration system that crosses jurisdictional boundaries is to be successful. An example of an administration system can be seen in the recent international recognition of the need for an SDI to manage and administer the rights, restrictions and responsibilities of the world's oceans (Ng'ang'a et al., 2001; Fowler and Treml, 2001; Williamson et al., 2001; Robertson et al., 1999).

There is also a need to understand the spatial dimensions of the marine environment both within a country and across a region, and this is one of the concerns of the United Nations (UN) supported Permanent Committee for GIS Infrastructure in Asia and the Pacific (PCGIAP). Common problems, issues, similarities and differences in institutional arrangements and in the administration of rights, restrictions and responsibilities need to be documented, in order for best practice to be established. There are also technology and human resource and capacity building issues effecting the establishment of effective

\begin{tabular}{|c|c|c|}
\hline Zone & Definition & Coastal State Jurisdiction \\
\hline $\begin{array}{l}\text { Territorial Sea } \\
\text { Baseline (TSB) }\end{array}$ & $\begin{array}{l}\text { The line from which the seaward limits of } \\
\text { maritime zones are measured, theoretically the } \\
\text { line of Lowest Astronomical Tide (LAT). }\end{array}$ & $\begin{array}{l}\text { The line from which the seaward limits of maritime } \\
\text { zones are measured }\end{array}$ \\
\hline Territorial Sea & $\begin{array}{l}\text { Band of ocean adjacent to the coastline, the } \\
\text { outer limit of which does not exceed } 12 \text { nautical } \\
\text { miles from the TSB. }\end{array}$ & $\begin{array}{l}\text { A nation has full sovereign rights within this area, } \\
\text { with the exception that it must allow foreign ships the } \\
\text { rights of innocent passage. }\end{array}$ \\
\hline Contiguous Zone & $\begin{array}{l}\text { Band of ocean adjacent to the territorial sea } \\
(12 \mathrm{~nm}) \text {, with the outer limit of the contiguous } \\
\text { zone not exceeding } 24 \text { nautical miles from the } \\
\text { TSB. }\end{array}$ & $\begin{array}{l}\text { A nation does not have sovereign jurisdiction over } \\
\text { this area, although is does have the right to enforce } \\
\text { its customs, fiscal, immigration and sanitary laws and } \\
\text { regulations }\end{array}$ \\
\hline $\begin{array}{l}\text { Exclusive } \\
\text { Economic Zone } \\
\text { (EEZ) }\end{array}$ & $\begin{array}{l}\text { Area stretching from the limit of the territorial } \\
\text { sea }(12 \mathrm{~nm}) \text { out to and not exceeding } 200 \\
\text { nautical miles from the TSB. }\end{array}$ & $\begin{array}{l}\text { A nation has the right to explore and exploit the living } \\
\text { and non-living resources of the water column, seabed } \\
\text { and subsoil. }\end{array}$ \\
\hline $\begin{array}{l}\text { Extended } \\
\text { Continental Shelf }\end{array}$ & $\begin{array}{l}\text { A nation may gain rights to an extended } \\
\text { continental shelf beyond the } 200 \text { nautical mile } \\
\text { limit, up to } 350 \text { nautical miles from the TSB, } \\
\text { subject to the provisions of Article } 76 \text { of } \\
\text { UNCLOS. }\end{array}$ & $\begin{array}{l}\text { Nations would gain seabed and subsoil rights to any } \\
\text { areas of an extended continental shelf granted under } \\
\text { UNCLOS. }\end{array}$ \\
\hline High Seas & $\begin{array}{l}\text { Area of ocean that falls beyond the Exclusive } \\
\text { Economic Zone, with the exception of areas } \\
\text { granted to nations under Article } 76 \text { of UNCLOS. }\end{array}$ & $\begin{array}{l}\text { All nations have equal rights and, subject to certain } \\
\text { provision, enjoy freedom of navigation, overflight, } \\
\text { fishing and scientific research. }\end{array}$ \\
\hline The Area & $\begin{array}{l}\text { The area is the seabed, ocean floor and subsoil } \\
\text { thereof beyond the limits of national } \\
\text { jurisdiction (United Nations, 1997). }\end{array}$ & $\begin{array}{l}\text { All nations have equal rights to the resources of the } \\
\text { Area. }\end{array}$ \\
\hline
\end{tabular}

Table 1. Jurisdictional Coastal Zones, as defined by UNCLOS (UN, 1997) 
marine administration systems that need to be taken into consideration. Perhaps the most important in creating an effective system however is investigating and solving socio-economic (institutional), policy and cultural issues that often hinder development long after technical problems have been solved, as seen in the terrestrial environment.

In order to develop a system that enables effective administration and management of environmental, social and economic factors within the marine environment, countries such as the USA, Australia and Canada are developing spatial boundary management systems for their jurisdictions. The titles of such systems vary, from marine SDIs to marine cadastres and marine GIS, but the aims of each system are closely aligned. These three countries are facing similar problems in relation to how to effectively manage offshore boundaries. There are multiple and unclear jurisdictional limits, various co-management arrangements, no single agency managing offshore rights and boundaries, indigenous title and enormous maritime areas to manage (Nicholset al.,2000).

Unlike some other regions, such as North America however, countries within Asia and the Pacific are at different stages of development and hence use and administer the marine environment in a diverse way. The world's oceans are also intrinsically linked, with activities conducted in one country having an effect on those in neighbouring countries. In order to address this, and in particular the use and management of spatial data, several international meetings and workshops, such as the joint University of New BrunswickInternational Federation of Surveyors (UNB-FIG) meeting in Canada 2003, have been conducted. This paper aims to discuss the issues stemming from such workshops, especially the PCGIAP-sponsored international workshop on Administering the Marine Environment-the Spatial Dimensionsheld in Malaysia in 2004. The socio-economic, policy and technical issues and challenges in administering marine activities are also defined and discussed, especially from the perspective of Asia and the Pacific region. Before discussion on issues and challenges however, an overview of the unique characteristics of Asia and the Pacific region is presented.

\section{ASIA AND THE PACIFIC REGION}

Asia and the Pacific region is the largest in the world with a vast geographic area of land and water, some 60 per cent of the world's population and 55 countries as defined by the United Nations (Rajabifard and Williamson, 2003). It is recognized that such different nations are at different stages of development, in terms of the administration of the marine environment. This is especially so within Asia and the Pacific region, with nations ranging from archipelagos to almost entirely landlocked. This requires a solution that is in one sense unique, but also flexible enough to take advantage of current international research.

To date most of the effort in administering the marine environment in Asia and the Pacific has been on defining claim boundaries and establishing the basis for those claims, as defined under UNCLOS. It is important however to demonstrate a capacity and intent to sustainably administer these areas. Thus far, with the exception of a few special areas, competing rights and responsibilities in Asia and the Pacific countries are handled in a somewhat ad hoc manner, with each responsible agency in the individual countries defining the spatial bounds of the given activity separately (Williamson et al., 2001). The recent adoption of the World Summit on Sustainable Development commitments for theSeas of East Asia at the East Asian Seas Congressis a step forward in addressing such areas. However there has been nomove to actively introduce a uniform and coherent infrastructure, such as an SDI, to support marine resource management.

An SDI would enable a more effective and efficient administration in support of marine resource management, especially in regards to rights, restrictions and responsibilities. The ability to clearly demarcate zones within the ocean, and access accurate and relevant spatial information are also primary aims of the infrastructure. It is also desirable that the management of the marine environment should be integrated with land-based information systems. This will aid in facilitating more integrated and effective approaches to coastal zone management, dealing with problems such as marine pollution from land based sources (Binns, 2004). 


\section{ESTABLISHMENT AND ACTIVITIES OF THE PCGIAP}

In order to improve understanding of the spatial dimensions of the marineenvironment, Working Group 3 (WG3) of the PCGIAP began working on aspects of marine cadastre and marine SDI in 2002.

The PCGIAP was established following theThirteenth United Nations Regional Cartographic Conference for the Asia-Pacific region (UNRCC-AP) in 1994 and consists of the national mapping agencies within each country in Asia and the Pacific region. The aims of the Committee are to maximise the economic, social and environmental benefits to geographic information in accordance with Agenda 21 by providing a forumfor all nations across the region to cooperate in the development of the Asia-Pacific Spatial Data Infrastructure (APSDI).

WG3 of the PCGIAP was established in the year 2000 based on Resolution 5 from the $15^{\text {th }}$ UNRCC-AP in Malaysia. Through that resolution, it was recommended that the UN, as part of its work plan for 2000-2004 and in cooperation with WG3 and with the expert assistance of relevant organisations such as the International Federation of Surveyors and the International Hydrographic Office $\left(15^{\text {th }}-\right.$ UNRCC-AP, 2000):

- undertake a study of land administration issues such as the range of tenure and institutional issues, water, indigenous, mining and petroleum rights, gender, urban conglomeration and land disputes with the objective of producing a global atlas and related documentation, utilizing the vast amount of existing land administration and land tenure data existing in United Nations agencies;

- facilitate discussion on marine cadastre and marine SDIs, focusing on the issues involved in the establishment of appropriate administrative infrastructures to manage marine resources in the context of the United Nations Convention on the Law of the Sea; and

- facilitate workshops to develop an appropriate generic template for county profile analyses describing the status of cadastre, land administration and marine administration, and the need for improvements, which will facilitate benchmarking and the development of performance indicators.

With this in mind, the PCGIAP, through its WG3, believes that facilitating discussion on marine administration is essential to the (Rajabifardet al., 2003):

- development of the Asia-Pacific Spatial Data Infrastructure;

- development of regional marine administration infrastructure;

- realisation of economic, social and environmental benefits for the region; and

- the implementation of the United Nations Conference on Environment and Development(UNCED) Agenda21;

and that:

- data sharing avoids wastefulduplication of resources and facilitates data integration; and

- provides better data for decision making and thus expands market potential.

\section{INTERNATIONAL WORKSHOP ON MARINE ADMINISTRATION}

As part of the Workplan, WG3 organised a four-day workshop ( $4^{\text {th }}-7^{\text {th }}$ May 2004) on Administering the Marine Environment-The Spatial Dimensions in Asia and the Pacific region. The workshop was conducted in Kuala Lumpur, Malaysia and hosted by the Department of Survey and Mapping Malaysia. The objective of the workshop was to better understand the spatial dimensions of administering the marine environment in Asia and the Pacific region and particularly to facilitate:

- an understanding of the needs of an SDI and cadastre in the marine context;

- a better understanding and appreciation of the administration of marine rights, restrictions and responsibilities and to agree on terminology; and

- the documentation of issues in establishing a marine dimension as a key component of NSDIs.

The workshop reviewed national administration of marineenvironments of countries in Asia and thePacific 
based on a common Marine Administration Country Template to identify problems, issues, similarities and differences in SDI; institutional arrangements; the administration of rights, restrictions and responsibilities; technology and human resource and capacity building. Over one hundred people attended the workshop from different countries and communities, with some presenting reports on their jurisdiction based on the country template. This template provides a basis for a comparative analysis of jurisdictions within Asia and the Pacific region. The PCGIAP-WG3 is continuing to promote countries to complete the Marine Administration Country Template in order to have a wider view of the management of the seas of Asia and the Pacific region. WG3 will also analyse the information gained from the country templates, as well as publishing them online. The web address for both the template and results is: http://www.marineadministration.org.

The workshop also presented an opportunity for countries to identify and present the most important issues and challenges affecting their marine SDI activities, and discuss and develop resolutions and recommendations to the PCGIAP on administering the marine environment. The three main areas of discussion focused on:

- issues in administering the marine environment;

- definition of marine SDI and marine cadastre; and

- administration of marine rights, restrictions and responsibilities;

with key outcomes represented in the form of resolutions, concentrating on issues in the region and particularly the role of marine SDI and marine cadastre in aiding more effective marine administration.

\section{Resolution 1 - Spatial Dimension of Administering the Marine Environment}

The workshop recommended that all countries in the Asia-Pacific region with an extensive marine jurisdiction and administrative responsibilities be encouraged to include a marine dimension in their NSDI as part of their obligation to meeting their responsibilities under UNCLOS.
And further recommended that they cooperate with other countries to ensure technical, operational and policy consistency in the marine elements of NSDIs developed in the Asia-Pacific region.

\section{Resolution 2 - PCGIAP-FIG Collaboration}

Due to theimportance of collaboration between different groups working on the same issues, the workshop recommended that PCGIAP and FIG collaborate through their respective work plans on marine cadastre, marine SDI, marine administration systems and ocean governance, and encourages the FIG to participate in the Marine Administration Template Project.

\section{Resolution 3 - Defining the Spatial Dimension of the Marine Environment}

The terminology used to describe the spatial dimensions of the marine environment was unclear, with participants having different understanding of the terms marine cadastre and marine SDI. Therefore, the workshop recommended that the term marine administration systemis adopted for the administration of rights, restrictions and responsibilities in the marine environment, with the spatial dimension facilitated by the marine SDI.

It further recommends that a marine cadastre is defined as a management tool which spatially describes, visualises and realises formally and informally defined boundaries and associated rights, restrictions and responsibilities in the marine environment as a data layer in a marine SDI, allowing them to be more effectively identified, administered and accessed.

\section{Resolution 4 - Requirement for Further Development of Guidelines and Tools to Administer the Spatial Dimension of the Marine Environment}

The workshop also recognised that more work needs to be done within Asia and the Pacific as a whole to more effectively manage the marine environment, and hence recommended that PCGIAP further investigates and develops guidelines and tools for administering the spatial dimension of the marine environment. 


\section{DISCUSSION}

The major areas of discussion at the workshop focussed on important points that need to be addressed in the context of effectively administering the marine environment. Although the issues raised were in the specific context of Asia and the Pacific region, they also tie in with the focus of other international meetings (such as the UN-FIG marine cadastre meeting) and research. The major points include:

- The environmental, social/economic and technical issues for administering marine activities

- Importance of including a marine component within the SDI policies as part of country's obligations to undOS

- SDI and cadastre are different and cadastral data can be a subset of SDI as well as a process based on SDI

- SDI should facilitate access, management and sharing of spatial data in both the marine and land environments at any jurisdictional/political levels

- A marine cadastre component of marine administration can include components of the land-based cadastre and, in addition, it must take into consideration the fuzzy nature of boundaries as well as a 3D (volume) and sometimes 4D (temporal) nature of the interests in the marine environment

- Importance of collaboration between FIG, Commission 4 and PCGIAP, Working Group 3(Cadastre) on issues relating to marine SDI and marine cadastre

- Lack of a single organisation capable of coordinating issues on marine environment

- Importance of institutional reform and capacity building in administering marine rights, restrictions and responsibilities

- The marine SDI should relate to natural boundaries as well as administrative boundaries.

The importance of understanding the link between land and marine environments (they cannot be treated in isolation) and the need for cooperation between nations as maritime actions transcend national boundaries was also a major topic of discussion (Figure 2). The need to assess current systems in order to identify socioeconomic, policy and technical issues hindering coordination and effective management of the marine

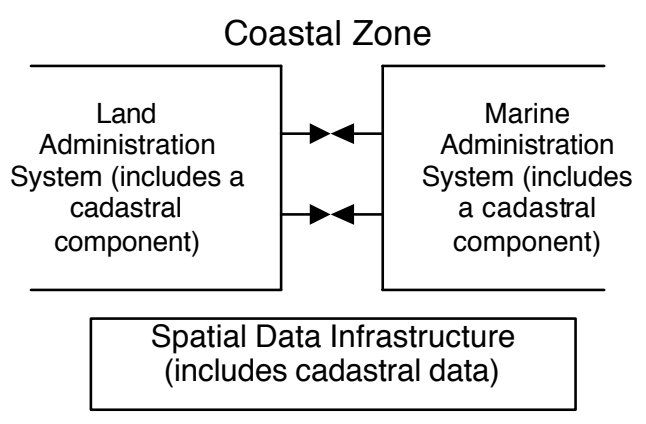

Figure 2. Importance of linking the land and marine environments

environment was also stressed and is discussed in more detail below.

\section{Socio-Economic and Policy Issues}

The need to take into account environmental, social and economic factors as well as technical issues is important if the objectives of sustainable development set out in documents such as Agenda 21 are to be met. In many parts of the world, and especially in Asia and the Pacific region, the ability to meet such sustainable development objectives must include respect for the needs, aspirations and interests of indigenous peoples. It was noted within the workshop discussion that most management frameworks to date tend towards atopdownapproach, where local indigenous peoples are often the passive recipients of policies, technologies and other instruments derived elsewhere. It is important to engage and include local communities, such as indigenous groups, in the administration of the marine environment.

The large variety of stakeholders within the marine environment was also a factor identified. The task of efficiently and effectively managing all stakeholders is complicated by the fact that their rights often overlap. Pressures on marine spaces also take place at multiple scales, both horizontally (geographically from global to the regional, national and local levels) and vertically (multiple pressures, operating over various spatial and temporal resolutions, all acting within the same geographic territory). Therefore, there is a need for mechanisms and structures for governance of marine 
territories that are sufficiently flexible to allow integration of global and international objectives with those of local communities and interest (PCGIAP-WG3, 2004).

The completion of the UNCLOShas given coastal States such as Australia the ability to increase the area of ocean territory under their control and with this comes increased areas to environmentally and economically exploit and explore. Oil and gas exploration are just one of the major sources of revenue for both government and private industry, with competition increasing for control over marine areas that are rich in such natural resources. This makes the effective management and delimitation of Australia's coastal area increasingly important. An example of the economic magnitude of the need to effectively administer marine spatial boundaries can be seen in the US Supreme Court case of United States of America v. State of Alaska (1975). According to Treml et al.,(1999) at issue was whether a small formation off the coast of Alaska qualified as an island. Oil and gas reserves worth $\$ 1.6$ billion were found nearby, and a 17-year court case followed, as both the state of Alaska and the USFederal Government fought over whohad the rights to the reserves. Spatial knowledge of legally defined boundaries needs to be available to both government and private users of the marine environment in order to avoid such issues occurring.

The creation of competing rights, restrictions and responsibilities in the ocean gives rise to the need for cooperation between agencies, something that can be difficult to achieve. This is invariably compounded by the lack of a single organisation (both government and industry based) capable of coordinating issues on marine management and administration. In order for this issue to be overcome, a whole-of-government approach to the management of a nation's marine environment is needed. This includes identifying organizations that have a mandate to manage marine datasets, overcoming laws and regulations that promote conflicts in marine spaces, and defining ambiguous terminology and spatial definitions within legislation (Collier et al., 2003). There must also be a shift in focus towards more forward looking and longerperspective management frameworks, rather than the historically reactive response to specific events. Within the context of marine SDI development, many of these issues are similar to those that land administration practicioners are also facing. This highlights the need to create a single mechanism for administering the spatial dimension of the environment through the SDI concept that spans both land and marine environments.

The creation of an effective SDI relies on the institutional capacity of organisations involved and the ability to create partnerships between all stakeholders. This will only come through breaking down the silo mentality of many of the institutions involved in marine management, just as is beginning to be done in the terrestrial environment. Whole-of-government approaches to managing spatial information in the terrestrial environment and the development of a vision for SDI development through land administration processes has aided in developing greater institutional capacity to effectively meet triple bottom line sustainable development objectives. The NationalOceans Office (NOO) has taken the lead in this respect within the marine environment but is limited legally to the marine area outwards of the 3 nautical mile zone. State governments and agencies operating within the 3 nautical mile coastal zone (where the majority of activity occurs), need to forge a strong partnership with the NOO in order to create a truly national partnership, which will result in more effective marine management.

\section{Technical Issues}

Spatial information technologies for managing coastal and marine information are now well established within most nations, however the knowledge required to use them appropriately and effectively is not, especially within Asia and the Pacific. Institutional reform, capacity building, education and training all need to be developed to address this gap.

One of the major technical issues discussed within the workshop and identified by researchers is that the nature of the marine environment is three dimensional, with different activities occurring on the surface of the ocean, across the water column and beneath the sea-bed. There are also instances in which a fourth dimension is introduced. An example can be seen in the 
techniques used to regulate fisheries, with some regulated seasonally, adding the advent of time over a three dimensional space. The modeling of such three and four dimensional spatial characteristics is a major hurdle to the development of a truly spatial representation of the rights, restrictions and responsibilities in the marine environment (Binnset al., 2004).

Issues of interoperability between technologies and datasets, as well as incompatibility of data formats, coordinate systems, geodetic parameters and other aspects of data pose further problems for data sharing and exchange both within and between nations. These issues are currently being addressed through the development of international standards and forums. Marine data collectors and managers however need to be aware of such standards for data capture, storage and exchange, and adhere to them.

Marine administration will be assisted by clear spatial definitions of existing rights, restrictions and responsibilities and a comprehensive structure for managing these spatial definitions. The termsmarine $S D I$ and marine cadastre are currently being used to describe the various marine boundary and spatial information systems being implemented by countries such as America, Canada and Australia. The workshop clarified the need to differentiate between the two. Resolution 3 recommended the term marine administration systembe adopted fortheadministration of rights, restrictions and responsibilities in the marine environment, with the spatial dimension facilitated by the marine SDI. SDI broadens the vision of existing administrations to include emerging technology and creates opportunities for sharing. The development of a marine component to existing NSDIs, in order to respond to socio-economic, policy and technical issues described above is important, and is discussed in more detail below.

\section{Marine SDI}

The development of most SDI initiatives throughout the world has focused mainly on land. This is despite the fact that nearly half of the world's population lives within 200 kilometres of a coastline (with this number likely to double by 2025) and the marine environment provides half of the food source for countries within Asia and the Pacific (Creel, 2003). As human pressure on coastal areas increases, identifying ways to balance people's needs while sustaining coastal resources is becoming more important.

The need for an SDI to manage and administer the rights, restrictions and responsibilities of the world's oceans has only recently received international recognition (Ng'ang'a et al., 2001; Fowlerand Treml, 2001; Williamson et al., 2001; Robertson et al., 1999). GIS and related technologies are becoming increasingly used to aid in the administration and management of the marine environment, and the development of an SDI will provide the foundation upon which such decision support tools can be based. This will aid in the development and creation of policies, planning and management tools and institutional frameworks necessary to achieve the environmental, social and economic objectives of sustainable development (Figure 3).

Within the PCGIAP, the 2002-2004 work-plan specifies the need for research into developing a marine dimension to the APSDI. Country specific initiatives, such as the development of Australia's marine cadastre, can be designed to tie in with any regional SDI.

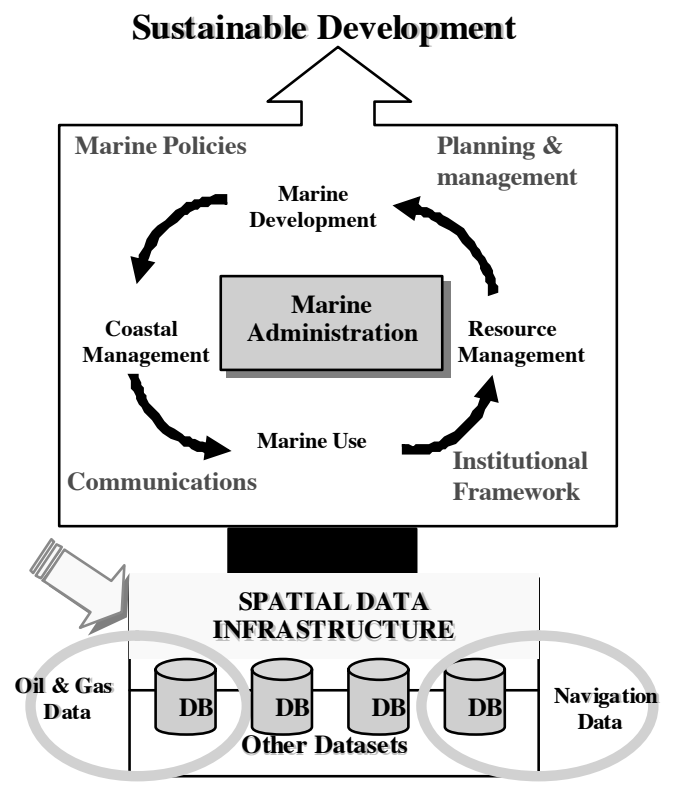

Figure 3. Marine SDI and Sustainable Development 
They will provide central registration, recording and monitoring of maritime rights, restrictions and responsibilities, integrate new and old leases and rights into a uniform spatial information system, and reconcile conflicts and incompatibilities in the management of spatial overlaps (Williamson et $\boldsymbol{a l}$., 2004). The definition of a country's maritime zones and zone boundaries within a uniform national reference system could also be implemented.

Coordination between jurisdictions and agencies is important, especially so within the Asian region, given the large number and closeness of State's maritime zones. The development of a regional SDI under the umbrella of the PCGIAP will aid in such coordination, providing interoperability of technologies and allowing better monitoring and enforcement of policies. The complex physical and institutional relationships that exist within the coastal zone make it impossible to develop a marine SDI in isolation from land-based national SDI initiatives. Such land based initiatives need to be expanded to include a marine SDI component due to the multiple physical and institutional spaces that exist within the coastal zone.

In order to effectively develop a marine component to the APSDI however, an understanding of the current administration of the marine environment throughout the region is needed. A steering arrangement, guided by international and national policy set at the highest level and working with existing agencies of international cooperation and local administrators can aid in developing an SDI vision (PCGIAP-WG3, 2004). This vision will assist in motivating governments of the need to develop guidelines appropriate to the region for the development of a marine element to the APSDI, concentrating on understanding the needs at a national level.

\section{CONCLUSION}

The need to administer the spatial dimensions of the marine environment is increasing, being driven mainly by the need to address environmental, economic and social issues of sustainable development, along with the need to break down data silos, creating easier access to accurate and up-to-date spatial data. The concepts discussed within this paper aim to deal with such factors, creating solutions to the effective management of the marine environment.

The recent meetings and workshops on administering the marine environment aim to tackle the development of effective marine administration systems in different jurisdictions. By reviewing the national administration of marine environments and identifying problems, issues, similarities and differences between them, appropriate guidelines can be developed to aid each nation in implementing a comprehensive SDI for their land and sea.

The need for a marine SDI is increasing. It must be remembered that most ocean and coastal management problems have a spatial element to them. Therefore, the development of National and Regional marine SDIs is imperative to the effective management of the marine environment. It is also important to understand the link between the terrestrial and marine environments, recognizing that they cannot be treated as separate entities. The development of a marine SDI within the context of current National SDIs developed for land based management will facilitate a more seamless integration of spatial data at the land-sea interface.

\section{ACKNOWLEDGEMENTS}

The authors would like to acknowledge the support of the International Sciences Linkages Programme, established under the Australian Government's innovation statement Backing Australia's Ability, UNPCGIAP, Department of Surveying and Mapping, Malaysia, and members of The MarineCadastre Research Group and Centre for SDIs and Land Administration at the Department of Geomatics, the University of Melbourne, in the preparation of this paper and associated research. The views expressed in the paper are those of the authors and do not necessarily reflect the views of these groups.

\section{REFERENCES}

Binns, A. (2004) Defining a Marine Cadastre: Legal and Institutional Aspects, Masters Thesis, The University of Melbourne.

Binns, A., Rajabifard, A., Collier, P., and Williamson, I. (2004) Developing the Concept of 
a Marine Cadastre: An Australian Case Study, Trans Tasman Surveyor, No. 6, pp. 19-27.

Collier, P.A., Todd, P.J. and Hirst, B. (2003) First Steps Towards an Australian Marine Cadastre, $1 \mathrm{st}$ National Spatial Sciences Conference 2003: Spatial Knowledge without Boundaries, Canberra. Creel,L. (2003)Ripple Effects: Population and Coastal Regions, Population Reference Bureau, $<w w w . p r b . o r g>$, Accessed $15^{\text {th }}$ April 2004.

Fowler, C. and Treml, E. (2001) Building a Marine Cadastral Information System for the United States - a Case Study,International Journal on Computers, Environment \& Urban Systems Special Issues: Cadastral Systems, 25 (4-5), pp. 493-507.

Ng'ang'a, S., Sutherland, M., Cockburn, S. and Nichols, S. (2001) Toward a 3D Marine Cadastre in Support of Good Ocean Governance, International 3D-Cadastre Symposium, 28-30 November 2001, Delft, Netherlands.

Nichols, S., Monahan, D. and Sutherland, M. (2000) GoodGovernance of Canada's Offshore and Coastal zone: Towards an Understanding of the Marine Boundary Issues, Geomatica, 54 (4) pp. 415424.

PCGIAP-WG3,(2004) Report on the International Workshop on Administering the Marine Environment-the Spatial Dimensions, KualaLumpur.

Rajabifard, A., Collier, P.A. and Williamson, I.P. (2003) Australian Marine Cadastre Research and Activities. FIG and University of New Brunswick Meeting on Marine Cadastre Issues, University of New Brunswick, Canada.
Rajabifard, A. and Williamson, I.P. (2003) AsiaPacific Region and SDI Activities, Journal of GIS Development, 7(7).

Robertson, B., Benwell, G. and Hoogsteden, C. (1999) 'The Marine Resource: Administration Infrastructure Requirements', UN-FIG Conference on Land Tenure and Cadastral Infrastructures for Sustainable Development, Melbourne, Australia.

Treml, E., Neely, R., Fowler, C., Smillie, H. and LaVoi, T. (1999) Spatial Policy: Geo-referencing the Legal and Statutory Framework for Integrated RegionalOceanManagement, Coastal Services Centre, National Oceanic and Atmospheric Administration, <http://www.csc.noaa.gov/opis/ $\mathrm{html} / \mathrm{>}$

UN (1997) 'United Nations Convention on the Law of the Sea', Publication No.E97.V10, United Nations, New York

15th-UNRCC-AP (2000) Proceedings of 15th United Nations RegionalCartographic Conference for Asia and the Pacific, Kuala Lumpur, E CONF.92/1

Williamson, I.P., Leach, J. and Rajabifard, A. (2001) Marine Cadastres. Position paper submitted to 7th Meeting of the Permanent Committee on GIS Infrastructure for Asia and the Pacific (PCGIAP), Tsukuba, Japan.

Williamson, I.P., Rajabifard, A. and Binns, A., (2004), Issues in Developing Marine SDI, Proceedings of International Workshop on Administering the Marine Environment - The Spatial Dimensions, KualaLumpur, Malaysia, $11 \mathrm{p}$. 


\section{University Library}

\section{- M M I N E R VA A gateway to Melbourne's research publications}

Minerva Access is the Institutional Repository of The University of Melbourne

Author/s:

Rajabifard, A.;Binns, A.;Williamson, I. P.

Title:

Administering the marine environment: the spatial dimension

Date:

2005

Citation:

Rajabifard, A. and Binns, A., \& Williamson, I. P. (2005). Administering the marine environment: the spatial dimension. Journal of Spatial Science, 50(2), 69-78.

Publication Status:

Published

Persistent Link:

http://hdl.handle.net/11343/33577 